\title{
First Trials with a 45 GW Cable-Based Pulsed-Power Generator
}

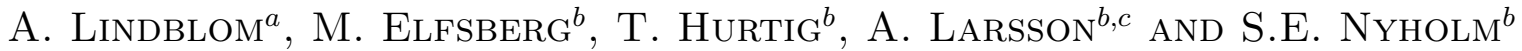 \\ ${ }^{a}$ ZpinchTech Engineering, SE-167 71 Solna, Sweden \\ ${ }^{b}$ Swedish Defence Research Agency (FOI), SE-147 25 Tumba, Sweden \\ ${ }^{c}$ Division of Electricity, Uppsala University, SE-751 21 Uppsala, Sweden
}

\begin{abstract}
The output from narrow-band high-power microwave (HPM) sources, such as the virtual cathode oscillator (vircator) and the magnetically insulated line oscillator (MILO), is strongly dependent on the voltage pulse feed. A rectangular, flat-top voltage pulse can be achieved by the use of a transmission line as a pulse-forming unit. The development in high-voltage cable technology has made them useful as parts of high-voltage and high-power generator systems. The generator is designed to deliver a 200 ns voltage pulse of $500 \mathrm{kV}$ into a $10 \Omega$ unmatched load with an electric power of $25 \mathrm{GW}$. The generator has an impedance of $2 \Omega$. The primary energy storage of the generator consists of a $50 \mathrm{kV}, 20 \mathrm{~kJ}$ capacitor bank. The $50 \mathrm{kV}$ is discharged into a transformer that charges a pulse-forming line to $550 \mathrm{kV}$. When charged, the pulse-forming line is discharged into the load via a spark gap. This paper presents results from initial testing of the generator.
\end{abstract}

PACS numbers: 84.30.Jc, 84.70.+p

\section{Introduction}

The pulsed-power generator is a vital component in systems for the generation of high-power microwave (HPM) radiation [1]. The output from narrow-band HPM sources, such as the virtual cathode oscillator (vircator) and the magnetically insulated line oscillator (MILO), is strongly dependent on the voltage pulse feed. For proper operation of these radiation sources, it is believed that the applied voltage ought to, in many configurations, have a rectangular and flat-top shape. This is generally true for the MILO but has yet to be verified for the vircator. Such a flat-top voltage pulse can be achieved by the use of a transmission line as a pulse-forming unit. Up to now, mainly water-based transmission lines have been used as high-voltage and high-power units. However, the development in high-voltage cable technology has made them useful as parts of high-voltage and high-power generator systems [2]. The idea of the design of the generator presented here is the outcome of a PhD Thesis $[3,4]$. The presentation here includes a concise description of the design of, and the initial tests with, the pulsed-power generator.

\section{Electrical design}

The design requirements of the generator were to deliver a 200 ns voltage pulse of $500 \mathrm{kV}$ into a $10 \Omega$ load with an electric power of $25 \mathrm{GW}$. These requirements were met by constructing a generator with an impedance of $2 \Omega$ that could be charged up to $600 \mathrm{kV}$.

The electrical design of the generator is shown in Fig. 1. The primary energy storage of the generator is a capaci-

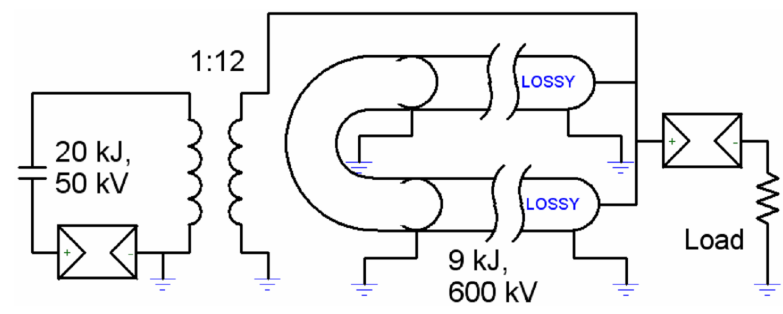

Fig. 1. The electrical design of the generator. The primary energy storage is a capacitor bank as shown on the left. The closing of the left-most spark gap discharges the capacitor bank into the transformer, which charges the $2 \times 8$ transmission lines. When the transmission lines are charged, the second spark gap is triggered and the voltage impulse is transferred to the load.

tor bank $(50 \mathrm{kV}, 20 \mathrm{~kJ})$ that is discharged via a closing switch into the primary side of a 1:12 pulse transformer $(L p=2 \mu \mathrm{H}, L s=270 \mu \mathrm{H})$. The primary and secondary sides of the pulse transformer consist of high-voltage cables that are interleaved. The high-voltage side of the transformer is connected to a pulse-forming line, which consists of 8 coaxial cables where the cables are grounded mid-way, resulting effectively in 16 cable segments in parallel. Since each cable has an impedance of $31 \Omega$, the total impedance of the pulse-forming line is $2 \Omega$. When the pulse-forming line has been charged, it is discharged into the load via a closing switch. The closing switch is a self-triggered spark gap immersed in water.

Equipment for monitoring the output voltage and current are integrated into the generator. The voltage over 
the pulse-forming line and the dummy load are measured using capacitive probes. The capacitive probes consist of thin copper foil strips and Mylar insulation. The current flowing from the pulse-forming line is measured by an in-house made Rogowski coil. The load used is a dummy load consisting of a $\mathrm{CuSO}_{4}$ water solution with a resistance of $10 \Omega$

\section{Initial testing}

Figure 2 shows the load voltage, $U_{\mathrm{L}}$, and the load current, $I_{\mathrm{L}}$, when the transmission line was charged to $460 \mathrm{kV}$. The current is multiplied with the load resis-

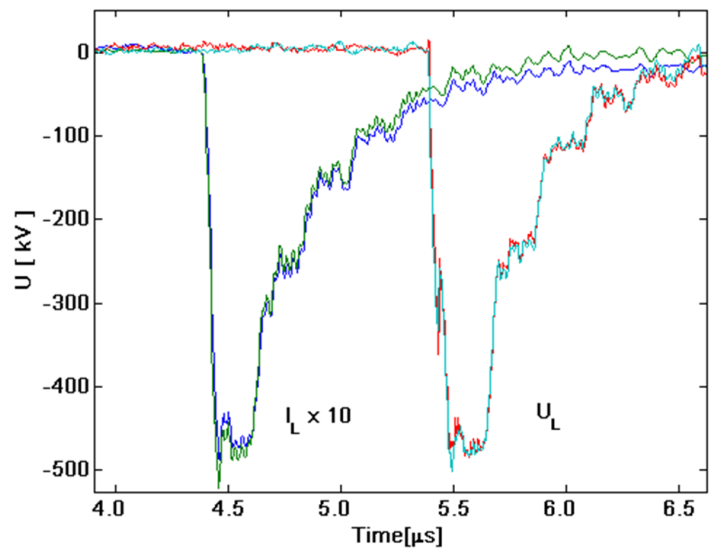

Fig. 2. Measurements of the load voltage, $U_{\mathrm{L}}$, and the load current, $I_{\mathrm{L}}$, multiplied with the load resistance when the transmission line is charged to $460 \mathrm{kV}$. The results from two shots are presented in the figure. The voltage and current traces are separated in time by $1 \mu \mathrm{s}$ in order to avoid having overlapping curves.

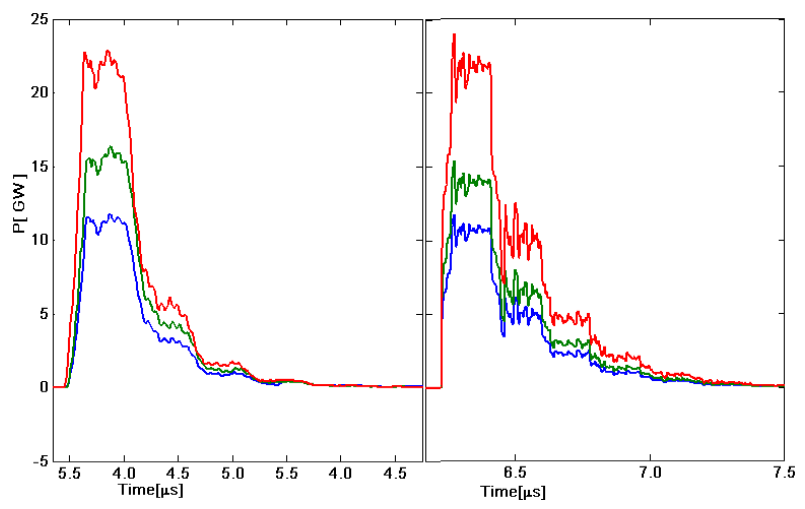

Fig. 3. Measurements (left) and simulations (right) of the load power for $360 \mathrm{kV}, 460 \mathrm{kV}$ and $550 \mathrm{kV}$ charging voltage of the transmission line, respectively. tance $(10 \Omega)$. The results from two different tests with the same charging voltage are given in the figure in order to demonstrate the low jitter of the self-triggered spark gap switch and the reproducibility of the load voltage. The voltage and current traces are separated in time by $1 \mu \mathrm{s}$ in order to avoid overlapping curves.

Measurements of the load power $\left(U_{\mathrm{L}} \times I_{\mathrm{L}}\right)$ from three tests are shown in Fig. 3 (left) where the transmission line is charged to $360 \mathrm{kV}, 460 \mathrm{kV}$ and $550 \mathrm{kV}$, respectively. The rise time (10\%-90\%) of the power is about $50 \mathrm{~ns}$ and the pulse width (FWHM) is about $225 \mathrm{~ns}$.

\section{Conclusions}

An equivalent circuit model of the generator has been developed and implemented in PSpice, and the simulations results are presented in Fig. 3 (right), where good agreement with the experimental data is found for the main power pulse.

The generator has been successfully tested with a $10 \Omega$ resistive load up to a load voltage of $470 \mathrm{kV}$. The measurements show that modern high-voltage cables can be used as pulse-forming transmission lines in high-voltage pulse generators.

\section{Acknowledgments}

This work has been supported by the Swedish Defence Materiel Administration (FMV) and the Swedish Armed Forces.

\section{References}

[1] J. Benford, J.A. Swegle, E. Schamiloglu, High Power Microwaves, 2nd ed., Taylor \& Francis, New York 2007.

[2] M. Leijon, M. Dahlgren, L. Walfridsson, Li Ming, A. Jaksts, IEEE Electrical Insulation Magazine 17, 10 (2001).

[3] A. Lindblom, Inductive Pulse Generation, Doctoral Thesis, Uppsala University, 2006.

[4] A. Lindblom, A. Larsson, H. Bernhoff, M. Leijon, IEEE Pulsed Power and Plasma Science Conference, Albuquerque, USA, 2007. 